Journal of Patient-Centered

7-19-2021

\title{
Business Cards as a Mechanism to Encourage Patient Feedback About Trainees
}

\author{
Marc Atzenhoefer \\ Jodie Ruffin \\ David Parewski \\ Nicole Deklotz \\ M. Fuad Jan \\ Ana Cristina Perez Moreno \\ Suhail Q. Allaqaband
}

Follow this and additional works at: https://aah.org/jpcrr

Part of the Cardiology Commons, Health and Medical Administration Commons, Health Services Research Commons, and the Medical Education Commons

\section{Recommended Citation}

Atzenhoefer M, Ruffin J, Parewski D, Deklotz N, Jan MF, Perez Moreno AC, Allaqaband SQ. Business cards as a mechanism to encourage patient feedback about trainees. J Patient Cent Res Rev. 2021;8:267-71. doi: 10.17294/2330-0698.1802

Published quarterly by Midwest-based health system Advocate Aurora Health and indexed in PubMed Central, the Journal of Patient-Centered Research and Reviews (JPCRR) is an open access, peer-reviewed medical journal focused on disseminating scholarly works devoted to improving patient-centered care practices, health outcomes, and the patient experience. 


\title{
Business Cards as a Mechanism to Encourage Patient Feedback About Trainees
}

\author{
Marc Atzenhoefer, MD, ${ }^{1}$ Jodie Ruffin, ${ }^{2}$ David Parewski, BBA,${ }^{3}$ Nicole Deklotz, MHA,${ }^{3}$ M. Fuad Jan, \\ MBBS (Hons), MD, ${ }^{1,4}$ Ana Cristina Perez Moreno, MD, PhD, ${ }^{5}$ Suhail Q. Allaqaband, MD ${ }^{1,4}$ \\ ${ }^{1}$ Aurora Cardiovascular and Thoracic Services, Aurora Sinai/Aurora St. Luke's Medical Centers, Milwaukee, Wl; \\ ${ }^{2}$ Institutional Medical Education, Aurora Sinai/Aurora St. Luke's Medical Centers, Milwaukee, Wl; ${ }^{3}$ Patient Experience, \\ Aurora St. Luke's Medical Center, Milwaukee, WI; ${ }^{4}$ University of Wisconsin School of Medicine and Public Health, \\ Madison, WI; ${ }^{5}$ Advocate Aurora Research Institute, Advocate Aurora Health, Milwaukee, WI
}

\begin{abstract}
This project sought to evaluate if business card distribution improved the utility of Hospital Consumer Assessment of Healthcare Providers and Systems (HCAHPS) surveys by serving as a feedback mechanism for trainees. Between fall 2018 and spring 2019, patient encounters for 6 cardiovascular disease fellows were tracked over two 60-day periods. Six weeks were allowed for HCAHPS surveys to be returned. Business cards were subsequently deployed and encounters similarly tracked. During the control-group monitoring period, 721 patient encounters were logged and 80 (11.1\%) surveys were returned. Qualitative feedback, in the form of free-response comments, was provided in $41(51.3 \%)$ surveys. Business cards were then deployed and encounters similarly tracked. During the business card period, 508 patient encounters occurred and 97 (19.1\%) surveys were returned. Qualitative feedback was provided in 52 (53.6\%) surveys. No fellow-specific feedback was returned in either group. Business card use by trainees was associated with an improved rate of survey return, from $11.1 \%$ to $19.1 \%$, but no effect on feedback to fellows or patient satisfaction scores was found. HCAHPS surveys were not useful in providing trainees with feedback. Immediate verbal feedback from patients via ancillary staff was observed. A method of relaying communication from patients to ancillary staff and medical education programs is needed. (J Patient Cent Res Rev. 2021;8:267-271.)
\end{abstract}

Keywords feedback; patient satisfaction; communication skills; domains of clinical competence; cardiovascular fellowship; graduate medical education

$\mathrm{O}$ ver the past decade the health care industry has undergone an electronic revolution. Increased use of computer-based medical records, procedure logging, and prescribing have added to the complexity of modern health care delivery. Some would argue that the physician-patient relationship has suffered as a consequence. ${ }^{1}$ This is of particular concern in an age in which patient satisfaction has become a central indicator of quality health care delivery in the United States.

Hospitalized patients in teaching institutions are commonly seen by multiple physician teams. As a result, patients often are unable to recall their physicians' names. ${ }^{2-4}$ Confusion often follows, especially upon

Corresponding author: Suhail Q. Allaqaband, MD, Aurora St. Luke's Medical Center, 2801 W. Kinnickinnic River Pkwy., \#880, Milwaukee, WI 53215 (wi.publishing3@aah.org) discharge, ${ }^{2}$ and this may affect outpatient follow-up and reflect negatively on patient satisfaction surveys.

The Accreditation Council for Graduate Medical Education (ACGME) outlines several domains of clinical competence that trainees should develop, ${ }^{5}$ including the domain of interpersonal and communication skills. Patient experience data are of particular importance in this domain. ${ }^{6}$ Although the ACGME supports the use of patient experience data in resident and fellow feedback, real-world mechanisms for obtaining and sharing this feedback are lacking. ${ }^{7}$ Business card use by residents has been shown to improve the patient experience ${ }^{8}$ and is thought to improve the physician-patient relationship. ${ }^{1}$

The following work describes our attempt to study and address the physician-patient relationship and patient satisfaction from the standpoint of feedback potentially given by patients to fellows-in-training. With the current emphasis on providing patient-centered care, it is imperative that large health care institutions address patient satisfaction whenever possible to improve care delivery and quality. ${ }^{9}$ 


\section{METHODS}

Patient encounters by 6 cardiovascular disease fellows on the consult and critical care services at Aurora St. Luke's Medical Center, a high-volume quaternary care center in Milwaukee, Wisconsin, were recorded between fall of 2018 and spring of 2019. Electronic medical record patient lists for the two separate services were monitored twice daily during two separate 60 -day periods. Patients added to these lists were noted for later matching with returned Hospital Consumer Assessment of Healthcare Providers and Systems (HCAHPS) surveys.

During the first 60-day monitoring period, a control group was established prior to deployment of business cards. Cardiovascular disease fellows interacted with patients on the consult and critical care services per their usual standard of practice. These fellows were aware that encounters were being tracked for research purposes but were blinded to the purpose of the study.

As per Centers for Medicare \& Medicaid Services guidelines, patients were selected at random to receive an HCAHPS survey by mail after hospitalization. The survey contains 27 standardized questions used to assess the hospital experience. The results of these surveys are publicly reported across the nation. From the date of the last recorded patient encounter, a 6-week period was allowed for the return of the randomly distributed surveys in each group. Surveys returned after this period were not included in the analysis (Figure 1).

After the establishment of a control cohort, business cards were delivered to all cardiovascular disease fellows irrespective of their rotation (clinical, invasive, imaging, etc). Business cards (Figure 2) displayed the fellow's name followed by a blank space for the inclusion of other cardiology team members (eg, resident/intern, medical student, attending physician). The back side of the business card read: "You may receive a survey in the mail regarding your stay. We would greatly appreciate any feedback and/or recognition of your care team."

Fellows assigned to consult or critical care services were briefed about the project and given daily reminders via the electronic messaging application WhatsApp to give business cards to their patients. WhatsApp is a free multimedia messaging application available on mobile and desktop devices. Transmissions via this application

\section{Study Start}

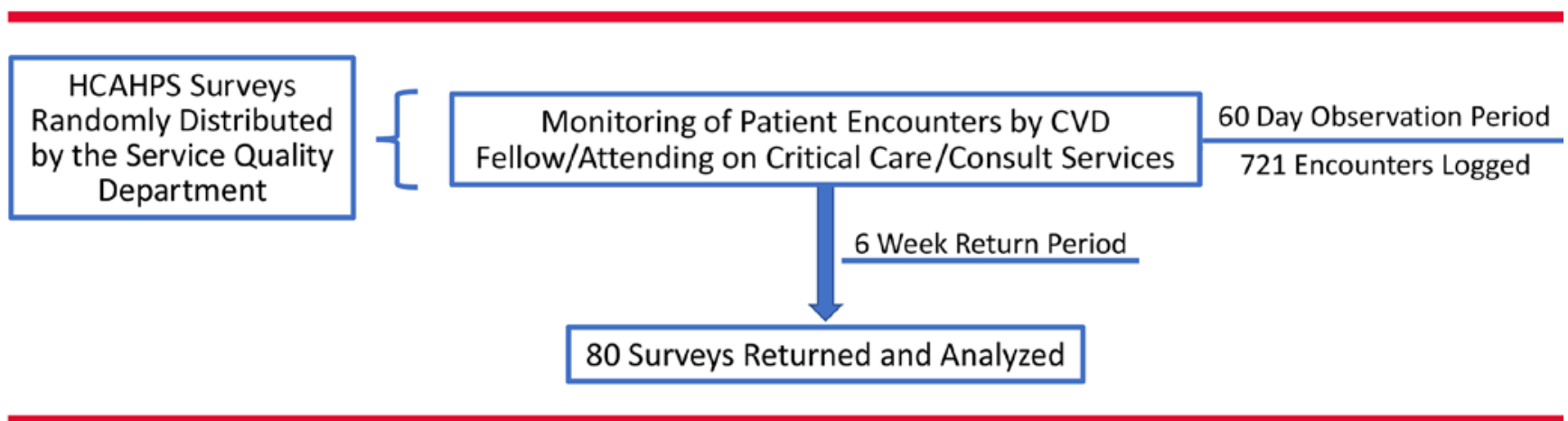

\section{Business Cards Given To Fellows}

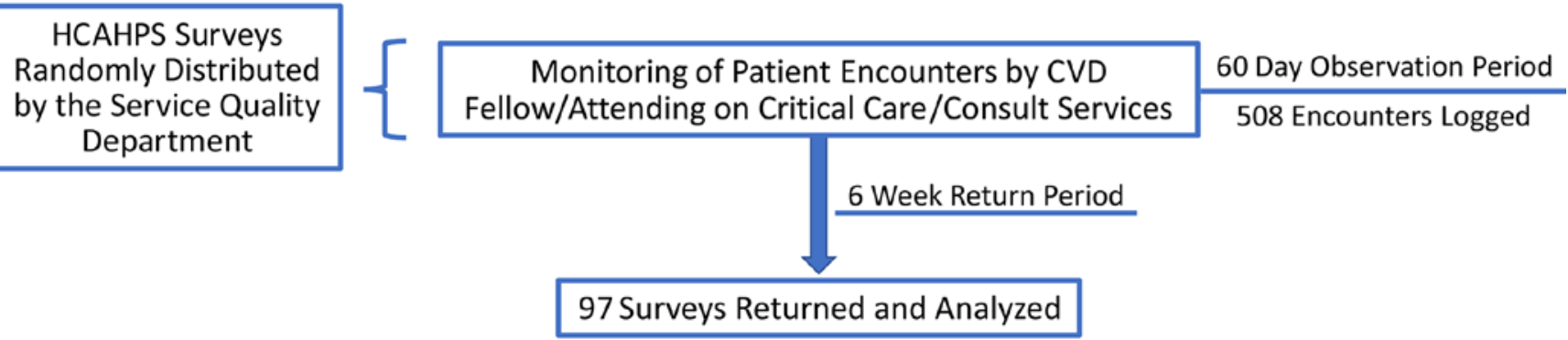

Figure 1. Outline of the process to establish control and intervention groups. CVD, cardiovascular disease; HCAHPS, Hospital Consumer Assessment of Healthcare Providers and Systems. 


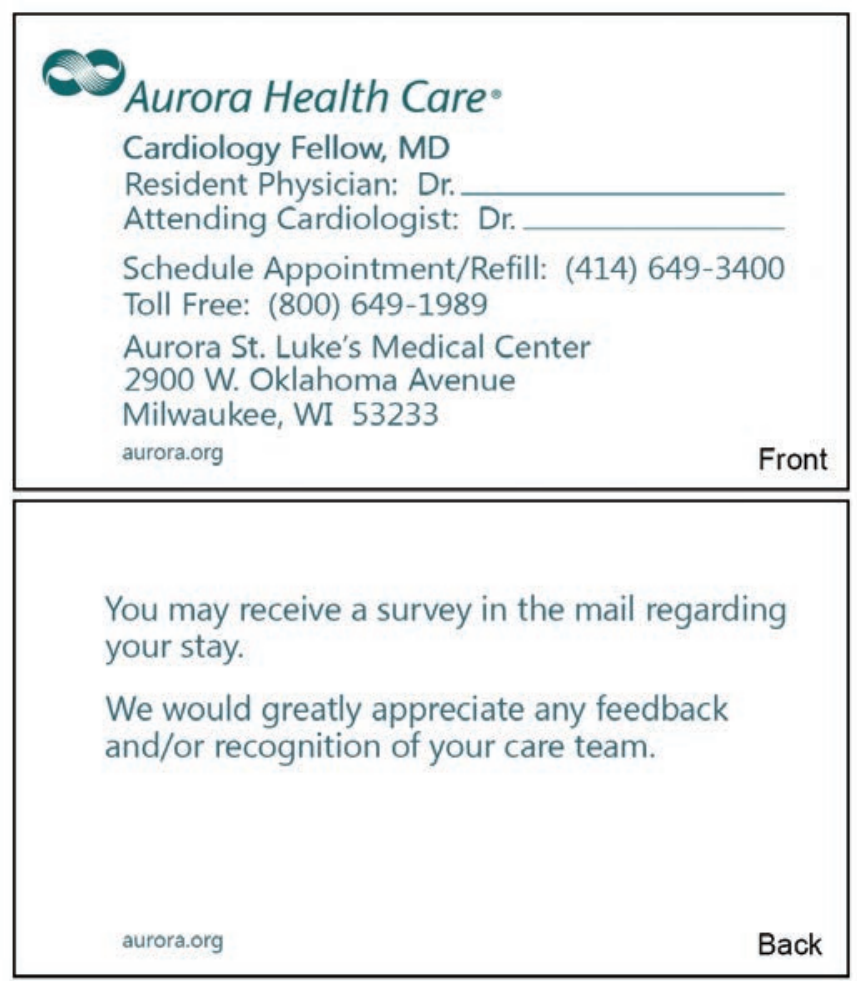

Figure 2. Example business card used for intervention arm.

are secured with end-to-end encryption, ensuring a private and reliable communication platform. To ensure recipient acknowledgement, read-report confirmations were enabled on all reminders.

The medical record number was used to match returned surveys with the relevant fellow-patient encounter. Surveys were analyzed for numerical response to 4 specific questions as well as qualitative content in the form of free-text feedback. Qualitative feedback was reviewed with special attention to any mention of cardiovascular disease fellows or other trainees.

The research proposal was reviewed and subsequently approved by our health system's research subject protection program and institutional review board.

\section{RESULTS}

During control-group monitoring, 721 patient encounters were logged. Among these, 80 (11.1\%) HCAHPS surveys were returned. Qualitative feedback was provided in 41 of $80(51.3 \%)$ surveys. No mention of trainee performance was noted.

During business card use, 508 patient encounters occurred and 97 (19.1\%) HCAHPS surveys were returned. Qualitative feedback was provided in 52 of 97 (53.6\%) surveys. No mention of trainee performance was noted. Due to absence of performance feedback, no analysis comparing control and intervention trainees could be conducted.

Analysis using Pearson's chi-squared test revealed a statistically significant difference in survey return rate $11.1 \%$ vs $19.1 \%(\mathrm{P}=0.003)$ - between the control and business card groups, respectively.

Responses to the following standardized HCAHPS survey questions were assessed on a scale of never/sometimes/ usually/always:

- During this hospital stay, how often did doctors treat you with courtesy and respect?

- During this hospital stay, how often did doctors listen carefully to you?

- During this hospital stay, how often did doctors explain things in a way you could understand?

Although a statistically significant difference was noted between the control and intervention groups, it was only seen in response to how well doctors explained things in a way that could be understood, for which the control group more frequently scored "always" while the intervention group more frequently scored "sometimes" (Table 1).

Table 1. Patient Ratings of Their Providers' Courtesy/ Respect and Willingness to Listen or Explain

\begin{tabular}{lccc}
\hline $\begin{array}{l}\text { Survey choices } \\
\text { by group }\end{array}$ & $\begin{array}{c}\text { Courtesy } \\
\text { and } \\
\text { respect }\end{array}$ & Listen & Explain \\
\hline Control $(\mathrm{n}=80)$ & & & \\
Always & $69(86.3 \%)$ & $66(82.5 \%)$ & $66(82.5 \%)$ \\
Sometimes & $9(11.3 \%)$ & $10(12.5 \%)$ & $11(13.8 \%)$ \\
Usually & $0(0 \%)$ & $3(3.8 \%)$ & $2(2.5 \%)$ \\
Never & $2(2.5 \%)$ & $1(1.3 \%)$ & $1(1.3 \%)$ \\
Intervention $(\mathrm{n}=97)$ & & & \\
Always & $79(81.4 \%)$ & $74(76.3 \%)$ & $62(63.9 \%)$ \\
Sometimes & $15(15.5 \%)$ & $19(19.6 \%)$ & $29(29.9 \%)$ \\
Usually & $2(2.1 \%)$ & $3(3.1 \%)$ & $5(5.2 \%)$ \\
Never & $1(1.0 \%)$ & $1(1.0 \%)$ & $1(1.0 \%)$ \\
\hline
\end{tabular}

$11.1 \%$ of patient surveys in the control group were returned vs $19.1 \%$ in the intervention group. No fellow feedback was included in surveys from either group.

Two comparisons yielded significant $P$-values of $<0.05$; these are indicated by the brackets. 
Recommend This Hospital

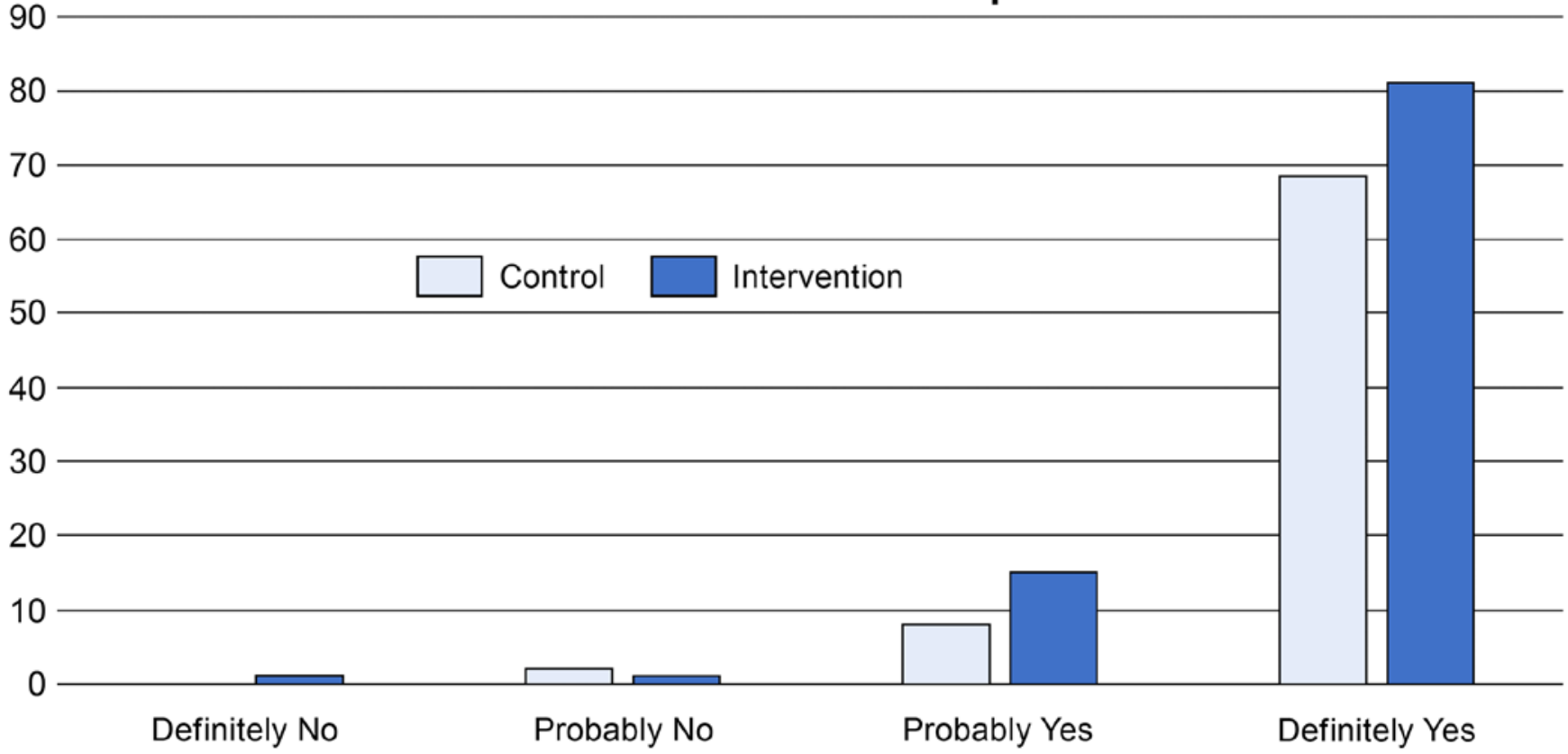

Figure 3. Percentile of patients who would and would not recommend our hospital. Comparisons were not significant in any category (ie, $P>0.05$ for all).

Regarding secondary analysis of patient satisfaction, $97 \%$ of patients in both control and intervention groups would "probably" or "definitely" recommend our hospital. When asked to rate our institution on a scale from 0 (worst possible) to 11 (best possible), a mean score of 10 was reported by both groups (Figure 3). This was consistent with the hospitalwide average reported across all specialties and services.

\section{DISCUSSION}

Business card use resulted in a statistically significant increase in the return rate of HCAHPS surveys. Unfortunately, no individualized feedback was provided by way of free-response text in the returned surveys. During the observation periods, unmeasured feedback provided to cardiovascular disease fellows from patients and their families was verbal and not directly studied. Often, a member of the nursing staff would relay a positive comment to the trainee from the patient or family. The absence of individualized feedback via HCAHPS is more than likely related to the time gap from fellow-patient interactions to patient receipt of the HCAHPS surveys via mail.

Despite careful selection of the 3 HCAHPS survey questions thought most likely to be affected by trainee use of business cards, our study did not show improvement in patient satisfaction. Of note, our study was not designed or targeted to impact patient satisfaction scores directly, but this was investigated as a secondary endpoint. Modern health care delivery is complex. Various providers from a multitude of teams interact with a single patient during their hospital stay, all of whom influence patient satisfaction, confounding the impact that business card use by fellows may have had.

\section{Limitations}

HCAHPS surveys are not designed for targeted feedback to medical trainees, and this likely played a role in our study's lack of results to that end. Furthermore, we were unable to confirm that patients eligible to receive a survey obtained a business card prior to discharge. The patients who did interact with the cardiovascular disease fellow could have been in multiple scenarios - admitted primarily under cardiology, seen in consult, etc. It is uncertain what effect business card use had on discharge follow-up. This could be considered in future studies.

The results of this study are limited to other quaternary care centers. Smaller community centers with fewer physician teams might have better results. Random distribution of surveys might have missed patient encounters that would have resulted in qualitative feedback to fellows. 


\section{CONCLUSIONS}

The use of business cards by trainees was associated with an increase in patient participation in the HCAHPS survey. However, HCAHPS surveys were not useful in providing feedback to cardiovascular disease fellows. Overall increased survey participation allows for a more accurate reflection of the average patient stay and can better guide changes aimed to improve patient satisfaction. Although not directly studied, immediate verbal commentary from patients via ancillary staff was a method of feedback for fellows. To effectively incorporate patient feedback into trainees' growth and development, a system of communication between ancillary staff and the medical education program is needed. This might be facilitated with a computer-based system like that frequently used in medical error reporting.

\section{Patient-Friendly Recap}

- Physicians-in-training enjoy feedback on their interactions with patients and need it to improve their bedside manners.

- Handing out business cards may encourage patients to fill out their HCAHPS (satisfaction) survey, which offers the means to give valuable feedback.

- However, this project found that surveyed patients generally do not provide specific comments about their encounters with cardiology fellows, regardless of business cards. Other methods are needed to help trainees advance their professional and communication skills.

\section{Acknowledgments}

The authors are grateful to Jennifer Pfaff and Susan Nord for editorial preparation of the manuscript and Brian Miller and Brian Schurrer for assistance with the figures.

\section{Author Contributions}

Study design: Atzenhoefer, Ruffin, Deklotz. Data acquisition and analysis: Atzenhoefer, Parewski, Deklotz, Perez Moreno. Manuscript drafting: Atzenhoefer. Critical revision: Jan, Allaqaband.

\section{Conflicts of Interest}

None.

\section{References}

1. Van Geertruyden PH. The AWOL business card. J Am Coll Radiol. 2018;15:1188-9. CrossRef

2. Arora VM, Schaninger C, D'Arcy $M$, et al. Improving inpatients' identification of their doctors: use of FACE ${ }^{\mathrm{TM}}$ cards. Jt Comm J Qual Patient Saf. 2009;35:613-9. CrossRef

3. Appel L, Abrams H, Morra D, Wu RC. Put a face to a name: a randomized controlled trial evaluating the impact of providing clinician photographs on inpatients' recall. Am J Med. 2015;128:82-9. CrossRef

4. Broderick-Forsgren K, Hunter WG, Schulteis RD, et al. Doctor who? A quality improvement project to assess and improve patients' knowledge of their inpatient physicians. J Grad Med Educ. 2016;8:197-201. CrossRef

5. Nasca TJ, Philibert I, Brigham T, Flynn TC. The next GME accreditation system - rationale and benefits. $N$ Engl J Med. 2012;366:1051-6. CrossRef

6. Bogetz AL, Orlov N, Blankenburg R, Bhavaraju V, McQueen A, Rassbach C. How residents learn from patient feedback: a multi-institutional qualitative study of pediatrics residents' perspectives. J Grad Med Educ. 2018;10:176-84. CrossRef

7. Campbell S, Goltz HH, Njue S, Dang BN. Exploring the reality of using patient experience data to provide resident feedback: a qualitative study of attending physician perspectives. Perm J. 2016;20:15-154. CrossRef

8. Spasic M, Lagman C, Chung LK, et al. Evaluating the use of business cards among neurosurgery residents and its impact on patient satisfaction. Interdiscip Neurosurg. 2017;8:68-71. CrossRef

9. Kupfer JM, Bond EU. Patient satisfaction and patient-centered care: necessary but not equal. JAMA. 2012;308:139-40. $\underline{\text { CrossRef }}$

(C) 2021 Advocate Aurora Health, Inc. 